\title{
Incidence of Post-spinal Hypotension during Cesarean Section in Paropakar Maternity and Women's Hospital
}

\section{Sangeeta Shrestha, ${ }^{1}$ Tara Gurung, ${ }^{1}$ Ritu Pradhan, ${ }^{2}$ Amir Babu Shrestha ${ }^{1}$}

'Paropakar Maternity and Women's Hospital,

${ }^{2}$ Bir Hospital, Kathmandu, Nepal

Received: 1 July 2018; Accepted: 20 November 2018

DOI: 10.3126/njog.v13i3.23508

\section{Author}

Dr Sangeeta Shrestha, MD

Assistant Professor, Consultant Anesthesiologist

Paropakar Maternity and Women's Hospital, Thapathali, Kathmandu Nepal Email: sang_2002@hotmail.com

Mobile No: 9851246774

\section{Co-Author}

Dr. Tara Gurung, MD

Assist. Professor (NAMS), Senior Consultant Anesthesiologist

Paropakar Maternity and Women's Hospital, Thapathali, Kathmandu

Email: grgtara@hotmail.com

Mobile No: 9841379504

Dr Ritu Pradhan, MD

Associate Professor (NAMS), Chief Consultant Anesthesiologist

Bir Hospital, Kathmandu, Nepal

Email: ritu_pn@hotmail.com

Mobile No: 9841348757

Prof. Dr. Amir Babu Shrestha, MD

Professor, Chief Consultant Anesthesiologist

Paropakar Maternity and Women's Hospital, Thapathali, Kathmandu Nepal

Mobile No.: 977- 9851066934

Email: ameer122@hotmail.com; amirbabu@gmail.com

Conflict of Interest: No

\section{CORRESPONDENCE}

Dr Sangeeta Shrestha

Department of Anesthesiology

Paropakar Maternity and Women's Hospital, Thapathali, Kathmandu Nepal

Email: sang_2002@hotmail.com

Phone: +977-9851246774 


\section{ABSTRACT}

Aims: Spinal anesthesia is the choice of anesthesia in parturient for cesarean section. This procedure is frequently associated with hypotension and the incidence varies from $70 \%$ to $80 \%$. Maternal hypotension causes very unpleasant sign and symptoms such as nausea, vomiting, dyspnoea and sense of impending doom. Prolonged episodes of hypotension lead to organ ischemia, loss of consciousness, cardiovascular collapse and uteroplacental hypoperfusion. The aim of this study is to find out the proper data of the incidence of hypotension in parturient undergoing cesarean section in our hospital as only the estimated data is present.

Methods: We retrospectively reviewed the intraoperative anesthesia record form of all the patients who underwent cesarean section under spinal anesthesia from the hospital record section from $13^{\text {th }}$ April 2016 to $12^{\text {th }}$ April 2017. The detailed parameters of patient's demographic data were collected and recorded.

Results: A total of 3814 parturients were included in this study. The mean age was $25.76 \pm 4.74$ years and mean gestational age was $39.23 \pm 1.54$ weeks. Post spinal hypotension was seen in 947 patients out of 3814 . Thus the incidence of hypotension was $24.8 \%$.

Conclusions: The incidence of maternal hypotension is very high if prophylactic measures are not taken. The fluid preloading or coloading, left lateral uterine displacement and prophylactic vasopressors have shown to be effective in preventing postspinal hypotension.

Keywords: cesarean section, incidence, post-spinal hypotension, spinal anesthesia

\section{INTRODUCTION}

Cesarean delivery is defined as the birth of an infant through incisions in the abdomen (laparotomy) and uterus (hysterotomy). It accounts for more than $30 \%$ of all births and is the most common surgical procedure performed in the United States, with more than 1 million performed each year. The rate of cesarean section in fiscal year 2016/2017 in Paropakar Maternity and Women's Hospital was $27.4 \%$

Spinal anesthesia is the choice of anesthesia in parturient for cesarean section because it is simple, easy to perform and have fast onset, a denser block, cost effective, less likely to fail i.e. reliable and avoids airway manipulation. The published data of the failure rate of spinal anesthesia is $<1 \%$., But, it is frequently associated with hypotension; audits incidence varying from $70 \%$ to $80 \%$. Besides sympathectomy, other causes of maternal hypotension are postulated to be due to compression of the vena cava by gravid uterus, venous pooling of blood in the lower legs leading to decreased venous return and reduced cardiac output. Maternal hypotension causes very unpleasant sign and symptoms such as nausea, vomiting, dyspnoea and sense of impending doom. Prolonged episodes of hypotension lead to organ ischemia, loss of consciousness, cardiovascular collapse and uteroplacental hypoperfusion. The aim of this study is to find out the exact data of the incidence of hypotension in parturient undergoing cesarean section in Paropakar Maternity and Women's hospital as only the estimated data is present.

\section{METHODS}

After approval from the institutional review committee of Paropakar Maternity and Women's hospital, we retrospectively reviewed the intraoperative anesthesia record form of all the patients who underwent cesarean section under spinal anesthesia from the hospital record department from $13^{\text {th }}$ April 2016 to $12^{\text {th }}$ April 2017 and enrolled them in our study. All the patients with age range of 17 - 40 years, single and full term pregnancy were enrolled in the study. The patients with pregnancy induced hypertension, preeclampsia, twin pregnancy, and those who received combination of spinal block with other type of anesthesia like epidural block and general anesthesia were excluded from the study.

The detailed parameters of patient's demographic data such as age, gravida, dosage of local anesthetic agent used, intravenous fluid, vasoactive and sedative agents used, total blood loss and any intraoperative complications were collected and recorded. All the patients were preloaded with $500 \mathrm{ml}$ ringer's lactate or normal saline and kept on left lateral uterine displacement after spinal anesthesia.

The baseline systolic blood pressure, diastolic blood 
pressure and heart rate were recorded and took as a reference control values. The lowest systolic blood pressure, diastolic blood pressure, heart rate and onset of that incidence were recorded. Post spinal hypotension was defined as systolic blood pressure $<90 \mathrm{mmHg}$ or mean arterial pressure less than or equal to $60 \mathrm{mmHg}$ and treated with Mephentermine $6 \mathrm{mg}$ IV bolus and that repeated to maximum dose of $30 \mathrm{mg}$ if needed, and intravenous fluids. Other intraoperative complication such as bradycardia, nausea and vomiting, shivering and pruritus were recorded. Bradycardia was defined as heart rate $<50$ beats $/ \mathrm{min}$ and treated with IV atropine $0.4 \mathrm{mg}$. Nausea and vomiting was treated with inj ondansetron $4 \mathrm{mg}$ IV and shivering was managed with inj pethidine 20 mg.

\section{Data Analysis}

All the parameters were recorded in Statistical Package for the Social Sciences (SPSS) version 22. Descriptive analysis was used for continuous parametric data like age, gestational age, dose of bupivacaine and fentanyl dose. Frequencies were used for analyzing incidence of hypotension and adverse effects. Chi square test was used to analyze the correlation of hypotension with types of surgery, fentanyl used and intraoperative complications such as nausea, vomiting, both nausea and vomiting and bradycardia. Results were presented in number (\%) for incidence of hypotension and adverse effects. $\mathrm{P}$ value $<0.05$ was considered as significant.

\section{RESULTS}

A total of 3814 parturients were included in this study. The demographic data showed the mean age as $25.76 \pm 4.74$ years with youngest of 16 years and oldest parturient of 45 years. The mean gestational age of the parturient was $39.23 \pm 1.54$ weeks [Table-1]. Nine hundred fifty seven (25\%) cases were elective caesarean section whereas 2857 (75\%) were emergency. There was no significant difference in hypotension between elective and emergency caesarean section [Table-2].

Table 1: Demographic data of the patients.

\begin{tabular}{|l|l|l|l|}
\hline \multicolumn{1}{|c|}{ Variables } & \multicolumn{1}{c|}{ Mean \pm SD } & Minimum & Maximum \\
\hline Age in years & $25.76 \pm 4.74$ & 16 & 45 \\
\hline $\begin{array}{l}\text { Gestational age } \\
\text { in weeks }\end{array}$ & $39.23 \pm 1.54$ & 31 & 43 \\
\hline
\end{tabular}

Table 2: Types of Surgery and hypotension.

\begin{tabular}{|l|l|l|l|l|}
\hline \multicolumn{2}{|c|}{} & \multicolumn{2}{l|}{ Types of surgery } & \multirow{2}{*}{ P Value } \\
\cline { 3 - 5 } & & Elective & Emergency & \\
\hline Hypotension & Yes & 248 & 699 & \multirow{2}{*}{0.369} \\
\hline & No & 709 & 2158 & \\
\hline
\end{tabular}

The average volume of $0.5 \%$ heavy bupivacaine was $2.09 \pm 0.18 \mathrm{ml}$; minimum volume used was $1.4 \mathrm{ml}$ and maximum used was $2.3 \mathrm{ml}$. Fentanyl was added in 1025 patients $(26.9 \%)$. The mean dose of fentanyl added was $0.4 \pm 0.02 \mathrm{ml}(20 \mathrm{mcg})$ [Table-3]. There was no significant difference $(\mathrm{p}=0.158)$ in hypotension with or without intrathecal fentanyl used [Table-4].

Table 3: Dose of bupivacaine and fentanyl used.

\begin{tabular}{|l|l|}
\hline Drugs & Mean \pm SD \\
\hline Heavy Bupivacaine $(\mathrm{ml})$ & $2.09 \pm 0.18$ \\
\hline Fentanyl $(\mathrm{ml})$ & $0.4 \pm 0.02$ \\
\hline
\end{tabular}

Table 4: Association of hypotension with fentanyl.

\begin{tabular}{|l|l|l|l|l|}
\hline \multicolumn{2}{|c|}{} & \multicolumn{2}{|l|}{ Fentanyl } & p- value \\
\cline { 3 - 5 } & & Yes & No & \\
\hline Hypotension & Yes & 274 & 673 & 0.158 \\
\hline & No & 762 & 2105 & \\
\hline & & & & \\
\hline
\end{tabular}

Post spinal hypotension was seen in 947 patients out of 3814 [Figure-1]. Thus the incidence of hypotension was $24.8 \%$. All the patients were treated with injection mephentermine. The mean dose of mephentermine used was $8.67 \pm 4.42 \mathrm{mg}$; minimum dose was $3 \mathrm{mg}$ and maximum $30 \mathrm{mg}$ and median dose was $6 \mathrm{mg}$.

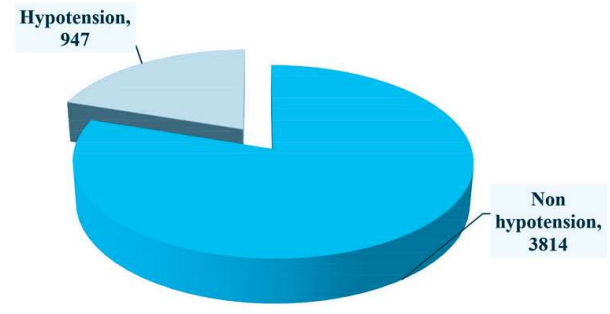

Figure 1: Incidence of hypotension.

Other intraoperative complications were observed [Figure-2]. Out of 3814 patients, 2567 patients $(67.3 \%)$ did not have any intraoperative complication. $4 \%$ (152) of parturient had shivering, $2(0.05 \%)$ had pruritus due to intrathecal opioid used, nausea in 65 $(1.7 \%)$ patients, vomiting in $54(1.41 \%)$, bradycardia was seen in $21(0.55 \%)$ patients, high block in 1 $(0.026 \%)$ and both nausea and vomiting in $5(0.13 \%)$ 
patients. Hypotension was significantly associated $(\mathrm{p}=<0.001)$ with vomiting and bradycardia [Table-5].

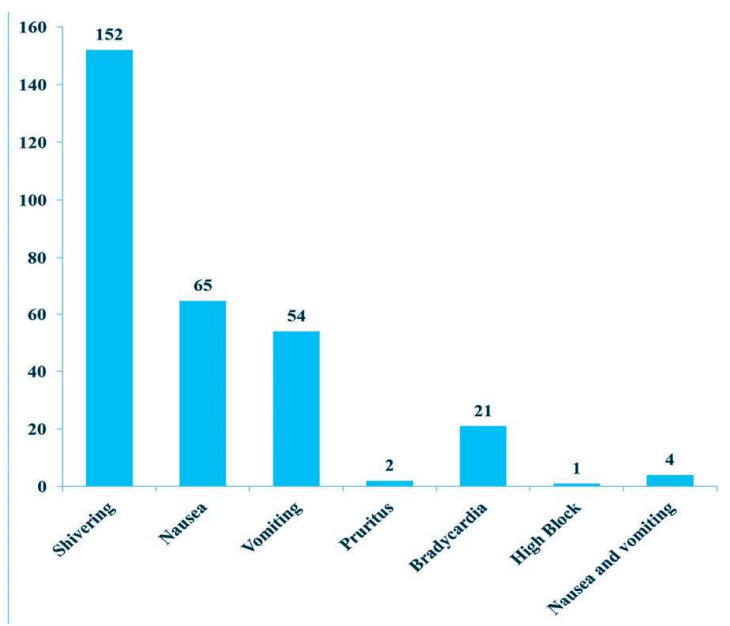

Figure 2: Intraoperative complication.

Table 5: Association of hypotension with complication.

\begin{tabular}{|l|l|l|l|l|l|l|l|l|l|}
\hline & \multicolumn{3}{|l}{ Nausea } & \multicolumn{2}{l|}{ Vomiting } & \multicolumn{2}{l|}{$\begin{array}{l}\text { Nausea and } \\
\text { Vomiting }\end{array}$} & \multicolumn{2}{l|}{ Bradycardia } \\
\cline { 2 - 11 } & Yes & No & Yes & No & Yes & No & Yes & No \\
\hline Hypotension & 22 & 925 & 40 & 907 & 1 & 946 & 16 & 931 \\
\hline & 43 & 2824 & 14 & 2853 & 4 & 2863 & 5 & 2862 \\
\hline p-value & 0.090 & & 0.000 & 0.802 & & 0.000 & \\
\hline
\end{tabular}

\section{DISCUSSION}

Post spinal hypotension is defined as systolic blood pressure less than $90 \mathrm{mmHg}$ or mean arterial blood pressure less than or equal to $60 \mathrm{mmHg}$. In literature the incidence of post spinal hypotension during cesarean section varies from $70-80 \%$ without any prevention. 6 But in this study the incidence of maternal hypotension was $24.8 \%$. This incidence was similar with the study done by Hemly NY et al in which they found the incidence of hypotension was $26.4 \%$. They had used maternal care bundle to prevent maternal hypotension after spinal anesthesia. In maternal care bundle, they used fixed low dose of bupivacaine $(7.5 \mathrm{mg}+$ fentanyl $25 \mathrm{mcg})$, coloading with $15 \mathrm{ml} / \mathrm{kg}$ lactated Ringer's, placement of the patient in the supine wedged position, administration of $9 \mathrm{mg}$ ephedrine sulphate IV after intrathecal injection and placement of graduated compression stockings (GCS) in the elevated leg position $>45$ degree and maintaining leg elevation at 20 degree following application of GCS. In our study we had preloaded all the parturient with $500 \mathrm{ml}$ Ringer's lactated or Normal Saline and manual left lateral uterine displacement as well as left table tilt.

Similarly Sharma NR also found the incidence of hypotension to be $38 \%$. In his retrospective study in 200 parturients, he did preloading with $300-500 \mathrm{ml}$ Ringers lactate and left lateral displacement of uterus. Thus preloading with intravenous crystalloids and left lateral displacement of uterine will reduce maternal hypotension.

In contrast to this study, Chumpathong $\mathrm{S}$ et al found that the incidence of maternal hypotension was $76.7 \%$ in their retrospective study in 991 patients. The incidence was high in their study compared to our study because they defined hypotension as systolic blood pressure $\leq 100 \mathrm{mmHg}$ where as in our study it was defined as systolic blood pressure $\leq 90 \mathrm{mmHg}$. They hadn't done preloading before spinal anesthesia. This may be the cause of increase incidence of hypotension in their study.

In this study hypotension was significantly associated with nausea and vomiting. Hypotension following spinal anesthesia at cesarean section causes both 
maternal and fetal adverse effects. So it should be recognized early and prompt management is necessary. Kinsella SM et al has recommended vasopressor to be used routinely and preferably prophylactically. $\alpha$ - agonist drugs are the most appropriate agents to treat or prevent hypotension after spinal anesthesia. Left lateral uterine displacement and intravenous colloid pre-loading or crystalloid coloading should be used in addition to vasopressors. The aim should be to maintain systolic arterial pressure at $\geq 90 \%$ of an accurate baseline obtained before spinal anesthesia and avoid to decrease to $<80 \%$ baseline.

Besides preloading of crystalloids and left uterine displacement, the incidence of hypotension in this study was $24.8 \%$. We have used mephentermine to treat hypotension. To reduce the incidence of hypotension we can changed our management. Despite of mephentermine we can use phenylephrine prophylactically as well as crystalloids coloading.

\section{CONCLUSIONS}

The incidence of maternal hypotension is very high if prophylactic measures are not taken. In our hospital the incidence was $24.8 \%$ with crystalloids preloading and left lateral uterine displacement. The fluid preloading or coloading, left lateral uterine displacement and prophylactic vasopressors have shown to be effective in preventing postspinal hypotension.

\section{REFERENCES}

1. Chestnut DH, Polley LS, Tsen LW, Wong CA. Chestnut's Obstetric Anestheisa Principles and Practice.4th ed. Mosby Elsevier ;2009 chapter 26.p.521

2. Berghella V, Baxter JK, Chauhan SP. Evidence-based surgery for cesarean delivery. Am J Obstet Gynecol. 2005;193:160717.

3. Annual Report (Smarika). Paropakar Maternity and Women's Hospital. 2074;p.58

4. Flood P, Rollins MD. Anesthesia for obstetrics. In: Miller RD, editor. Miller's anesthesia. 8th ed. Philadelphia, PA: Elsevier; 2015. p. 2704-40.

5. Ferne R. Braveman BMS, Marcelle E. Blessing,Cynthia A Wong. Obstetrical anesthesia. In: Paul G. Barash MKC, Bruce F. Cullen,M. Christine Stock,Robert K. Stoelting,Rafael Ortega., editor. Clinical anesthesia. Philadelphia, PA: Lippincot Williams \& Wilkins; 2013. p. 1144-77.

6. Loubert C. Fluid and vasopressor management for Cesarean delivery under spinal anesthesia: continuing professional development. Can J Anaesth. 2012;59:604-19.

7. Shibli KU, Russell IF. A survey of anaesthetic techniques used for caesareansection in the UK in 1997. Int J ObstetAnesth 2000;9:160-7

8. Hideyuki H, Shunichi T, Kan Z, Ikue F, Makoto O. Effect of lateral tilt angle on the volume of the abdominal aorta and inferior vena cava in pregnant and nonpregnant women determined by magnetic resonance imaging. Anesthesiology. 2015;122(2):286-93

9. Macarthur A, Riley ET. Obstetric anesthesia controversies: vasopressor choice for postspinal hypotension during cesarean delivery. Int Anesthesiol Clin. 2007;45:115-32

10. Hemly NY, Ibrahim JH, Salama AK, Mahrous AM. Maternal care bundle; The effect of a multimodal approach on the prevention of maternal hypotension following spinal anesthesia in parturients undergoing elective or urgent cesarean section. Egyptian Journal of Anaesthesia. 2017;33:171-4

11. Sharma NR. Incidence of postspinal hypotension during cesarean section. Journal of Institute of Medicine. 2005;27:3133.

12. Chumpathong $\mathrm{S}$, Chinachoti $\mathrm{T}$, Visalyaputra $\mathrm{S}$, Himmunngan $\mathrm{T}$. Incidence and risk factors of hypotension during spinal anesthesia for cesarean section at siriraj hospital. J Med Assoc Thai. 2006;89(8):1127-32

13. Kinsella SM, Carvalho B, Dyer RA, Fernando R, McDonnell $\mathrm{N}$, Mercier FJ, et al. International consensus statement on the management of hypotension with vasopressors during caesarean section under spinal anaesthesia. Anaesthesia 2018;73:71-92. 